\title{
An Overview of Research on Film Grading and Censorship in Major Countries of the World
}

\author{
Ting Liu \\ School of International Law \\ Shanghai University of Political Science and Law \\ Shanghai, China
}

\author{
Xiao $\mathrm{He}$ \\ School of Foreign Languages \\ Shanghai University of Political Science and Law \\ Shanghai, China
}

\begin{abstract}
Countries in the world have adopted legal measures to conduct film classification and censorship. Whether in the birthplace of the film or in the flourishing place of film development, film censorship and classification as an institutional tool can not only protect the legitimate rights and interests of minors, but also play an important and irreplaceable role in social norms and even ideology. The censorship and classification system of the film does vary according to the degree of development of spiritual civilization and material civilization in different countries. Based on this reality, it is necessary to establish a film classification and censorship system in China as soon as possible.
\end{abstract}

Keywords—film classification; film censorship; legal guidance

\section{INTRODUCTION}

As an important entertainment method in modern life, film not only enriches people's spiritual life, but also becomes an important media for information dissemination. However, the clustering, the globalization trend and the ideology complexity of the film industry have also brought about many social problems, especially the protection of minors. The filmrelated laws are not matched, and the role of legal guidance is not clear, which has been a bottleneck for the orderly and healthy progress of the film industry. Based on this practical need, all countries in the world have adopted legal means to conduct grading and review. The existing grading and review policies and legal regulations have entered a predicament": on the one hand, with the film industry developing rapidly, the government support and legal guidance are in urgent need. On the other hand, an overly strict grading and censorship system will constrain the development and artistic creation of the film industry. At present, the scholars of various countries have a fragmented state in the study of the policy and legal regulation of film grading and censorship, lacking systematic research on the industry. The current literature mainly focuses on the research about the film censorship in various countries. Scholars from all countries hold different attitudes towards film grading and censorship.

\section{THE HistORICAL EVOLUTION OF FILM GRADING AND CENSORSHIP IN FRANCE - THE BIRTHPLACE OF FILM}

The film was born in France in 1895. France's management of film and television works actually appeared in the First World War. It was mainly to control the violent and cruel photographic and video works during the war to avoid psychological trauma or war weariness of watcher, but at the time there was no independent review department. Remi Fournier Lanzoni (2009) pointed out that on July 25, 1919, the French government stipulated that in addition to news films, any film must be in public screening only after it and its name have obtained permission certificate of the "Public Education and Beauty Art Department". This is also the earliest decree of the French government on the censorship system. ${ }^{1}$ In 1946, the Centre National De La Cinematographie (CNC) was established. In order to protect the children audience in the cinema, the "Review Committee" was also set up. The period from 1961 to 1990 was considered perfection stage of the censorship system. In 1961, the Review Committee determined the age criteria for grading to be 13 and 18 years old, and the standard was followed for the next 30 years.

After the May 1968 Events, French Marxist Criticism emerged. The French leftist film critic was influenced by Karl Marx and began to link film with ideology followed by developing a rigorous ideology about film, ideology and political relations, which was regarded to be mingled with Freudianism. Christian Mets (1968) held that since the film should always choose what to present and not to present, the world has been transformed into some arguments. Because all films are carriers of ideology, it means that in addition to economic and political censorship, film censorship has an ideology and moral review, which means self-reflection. These three types of examinations intervened in the entire process of conception going into films, and through accurate divisions of labor, the films are arranged into a "natural" hierarchy, effectively conducting constraint. The political review on the original meaning distorted the distribution of the film; the economic review damaged the film production; and the ideological review ruined the creation. ${ }^{2}$

In 1975, Jacques Chirac, who firstly served as the French prime minister, issued a bill to classify pornographic films as $\mathrm{X}$-level and to specialize in the distribution of pornographic films. Zhu Hong (2011) argued that in December 1975, the French House of Representatives voted to adopt regulations

Remi Fournier Lanzoni: "French Film — from Birth to the Present", The Commercial Press, 2009: 21

2 Christian Mets. Essais sur la signification au cinema, Paris: Klincksieck,1968 
on pornographic movies and violent movies, increasing the income tax rate of pornographic films, and raising the loan interest rate on pornographic videos. ${ }^{3}$ In the late 1980 s, JeanFrançois Terry initiated a proposal for restructuring and reforming Review Committee, which was finally realized in 1990. He thought that the previous Review Committee was too conservative on the age standard for grading. So since 1990, the French film grading system has changed the age standard to 12 and 16 years old. The Review Committee of $\mathrm{CNC}$ always has the power of rejecting a film to be released in France, but no such incident has taken place yet.

\section{The EVOLUTION OF FILM GRADING AND CENSORSHIP IN THE UNITED STATES - THE MOST DEVELOPED COUNTRY OF THE FILM INDUSTRY}

The formation of American film grading and censorship has undergone a tortuous process. The film was born in France in 1895. And the "Populace and Doris Case" in 1897 in the United States was considered the starting point for American film censorship. In this case, the New York judge considered a film describing the bride's wedding night to be infuriating. Since then, Burch Noel (1993) pointed out in the book "Reviewing Hollywood: New British and American Criticism" that after the case occurred, local measures were introduced more and more frequently. These measures prohibited all so-called "immoral or embarrassing" films, especially those of "acting evil, criminal or morally absent". 4

Then it developed rapidly in the United States. In order to control the playback of film content, the Chicago City of the United States first established the Film Inspection Committee in 1907. But it still can't stop the shooting and screening of crime, sex, love and other topics in commercial movies. In 1934, the Hayes Code came into practice, which carried out strict control of the Hollywood film. Roland Lacourbe (1985) mentioned that in order to strengthen the Hayes Code to implement new norms in the film story, the US House UnAmerican Activities Committee (HUAC) at that time began to clean out the -Cmmunists" from the Hollywood film industry by claiming that the national security was threatened so that a large number of leftist artists were implicated. ${ }^{5}$ The practice of the US government during this period was called "McCarthyism".

In the 1960s, the establishment of the American Film Institute's grading system replaced the Hayes film censorship system. In 1965, the US Supreme Court ruled that the review committees of local governments must approve the film release in a timely manner. If a film is to be rejected, it must be brought to court, and the burden of proof of "obscene" works is on the side of the government censor. After this ruling, the film review committees around the country gradually disappeared. In 1968, Motion Picture Association of America (MPAA), a non-governmental organization,

Zhu Hong: History of Contemporary French Film (19591980)",Beijing: Communication University of China Press, 2011:163

Burch, Noel (textes choisis, traduits et présentés par), Revoir Hollywood: la nouvelle critique anglo-américaine, Nathan, Paris, 1993.

R. La Guerre froide dans le cinema d'espionnage, Paris: Henri Veyrier. Lacourbe, R. (1985) advocated a voluntary grading system. The Association's CARA was responsible for rating movies. Regis Dubois (2014) believes that since then, the film grading system has been relaxed, ethical standards have been changing, and censorship has become more rigorous and binding. ${ }^{6}$

\section{RUSSIAN FILM GRADING SYSTEM}

Russia is a world-recognized big movie country. The film of the former Soviet Union started very early, almost the same as the history of the film itself. Former Soviet film director Eisenstein's work "Bronenosets Potyomkin" is still an educational works of the film discipline. Developing to today, Russian films still inherit the tradition of the former Soviet ones. The Russian film industry has a profound cultural heritage and industrial base. However, unlike many countries in Europe and the United States, the Russian film law does not reflect the grading requirements for movies. The true law on film grading is mainly reflected in the federal law Regulations to Protect Children from Information Harmful for Their Health and Development implemented on September 1, 2012, there are currently five grades currently:

First, information products for children between the ages of 0 and 6: information products for children under the age of six contain information that does not harm the health and/or development of the child (including ones composed of sporadic non-naturalistic images or describing the body and/or spirit violence (excluding sexual violence). And their type and/or plot are proved on their reasonableness; ones that goodness defeats evil, and expresses sympathy for victims of violence and/or condemnation of violence.)

Second, information products for children over 6 years old: short-term and non-naturalistic images or descriptions of human diseases (except for serious illnesses) and/or their consequences, in a form that does not diminish human dignity; an unnatural image or accident, a description of the accident, a catastrophic or non-violent death without proving the consequences, which can cause fear or panic in the child; do not induce anti-social behavior and/or criminal plot images or provide descriptions of these behaviors and/or crimes that are not justified or reasonable and expressed. In the mean time, it's wise to have a negative attitude and take a condemnation towards those who commit these crimes.

Third, information products for children over the age of 12 cruel and/or violent plot images or descriptions (other than sexual violence) without the deprivation of life or deprivation process of naturalistic expression, as long as expressing sympathy and/or denial to the victim, condemn a cruel, violent attitude (except violence) that applies to cases protecting civil rights and legally protected interests. The society (or state) discourages antisocial images or description actions (including drinking alcohol and alcoholic products, beer and beverages produced on this basis, involved in gambling, professional wandering or begging), and those information that accidentally mention (without demonstration) narcotic drugs, psychotropic substances and / or poisoning

\footnotetext{
Regis Dubois: Hollywood - Film and Ideology. The Commercial Press, 2014 (7).
} 
substances, tobacco products, but allows unreasonable expression of anti-social behavior. The negative and condemned attitudes for them indicate the dangers of using these products, funds, substances, products; does not rule out sexual interest, and there is no exciting or offensive plot of unnaturalistic image or description of sexual relationships between men and women, except for images or descriptions of sexual behavior.

Fourth, the information products for children over the age of 16: the shaping or description of misfortunes, accidents, disasters, diseases, deaths, without natural manifestations of their consequences, which may lead to children's fear or panic.

Fifth, for children over the age of 18 , the distribution of information products to children is prohibited. It's forbidden to encourage children to engage in behaviors that threaten their lives and/or health, including harming their health, suicide and promoting lesbian and gay social culture. Those able to enable children to use narcotic drugs, psychotropic substances and/or intoxicating substances, tobacco products, alcoholic and alcoholic products, beer and beverages based on them, gambling, prostitution, and animals intimacy, except as provided by federal law; denying family values and disrespecting for parents and/or other family members; containing pornographic information and visceral open images; contains crude language and other abusive words are prohibited. Information that defies crime, cruelty and other illegal acts, and depicts the consequences of bloody violence that does not rule out sexual violence is not allowed.

\section{THE STARTING POINT FOR RATINGS AND REVIEWS: SOCIAL ISSUES RELATED TO MOVIES}

For women's rights, children's rights and freedom of speech related to movies, Lawrence M. Friedman (2014) considered that the protection of children's behavioral ethics is an important theme for regulating film activities. Movies have a lot of negative effects on children: for example, they interfere with children's sleep habits; many juvenile offenders" have learned -riminal means" from movies; they stimulate people's excessive desires and eventually lead to erime". Protecting children is of course the main motivation, but in the mean time, it also protects the public. Because the purpose of legal review is not only to safeguard children, on the issue of speech liberty, he pointed out that the position of the US Supreme Court is clear: the law does not have the right to offend freedom of speech. But because the film may be "used for evil purposes," the state has the right to manage it. ${ }^{7}$

Regarding racial discrimination in the film and related entertainment industries, Nicholas D. Kristof (2006) deemed that in today's society, so-called customer preferences influence the ethnic boundaries of the film. In essence, race is increasingly affecting entertainment in a more complicated way. He focused on statutory law and case law on employment discrimination based on customer preferences; and relying on the First Amendment to the US Constitution, he examined how and why current laws should be used to

Lawrence M. Friedman. Human rights, freedom of expression, and the rise of the silver screen, Hofstra Law Review, 2014. eliminate discriminatory decisions based on customer perceived preferences. Eventually the philosophical issue of law and morality was reached. ${ }^{8}$

Jonathan Todres (2015) believed that the film aggravated human trafficking. He pointed out that the US federal antitrafficking law has undergone great changes, and all 50 states have passed legislation to combat such serious human rights violations. But the problem of human trafficking is still very serious because the social problem is becoming a hot topic in the film industry. The film plays an important role in hiding problems and raising public awareness. Movies often lead to misunderstandings about many things: for example, trafficking in persons is only for sexual exploitation; only women and children are victims of human trafficking; the victims of human trafficking are mostly white people. Trafficking-related exploitation is rooted in other cultures, not its own culture; every human trafficking can be saved.

It's better for scholars to attach more importance on the unmatching between the description of human trafficking and the reality of the problem in movies (and other media). Researchers and advocates can use the film to provide an opportunity to educate the public about the realities of the problem. Movies and television can be powerful tools for education, but it is important to ensure that they are used effectively. For researchers and advocates, human trafficking films are useful tools to conduct more inclusive discussions on the realities of human trafficking and to respond comprehensively to current issues. ${ }^{9}$

Lucille M. Ponte (2008) was more concerned about movie piracy. He pointed out that the film industry faces global film piracy. The film industry has sought to sue film consumers and open content sites (such as YouTube) for copyright infringement and promote international law enforcement, using public resources to investigate and prosecute infringers. Under the impetus of the Motion Picture Association of America (MPAA), US federal and international law enforcement agencies have cooperated in copyright infringement investigations and prosecutions, and have ransacked dozens of countries in various enforcement actions to curb piracy. A recent US complaint filed with the WTO stated that China's efforts to sue film piracy in its territory were insufficient. ${ }^{10}$

\section{THE OPERATION OF FILM GRADING AND CENSORSHIP}

Proponents of the film censorship and grading system are generally concerned about the protection and behavioral guidance of minors. Richard Potts and Angela Belden (2009) argued that the purpose of film ratings is to limit underage children to watching films that are not suitable for their age.

8 Battles Ben. Terror, Tort, and the First Amendment, Brooklyn Law Review, 2006. In this article, Battles Benzai critically accepted the view of Nicholas D. Kristof.

Jonathan Todres. Human trafficking and film: How popular portrayals influence law and public perception, Cornell Law Review Online, 2015.

10 Lucille M. Ponte .Coming Attractions: Opportunities and Challenges in Thwarting Global Movie Piracy, American Business Law Journal, 2008 
They believed that the Motion Picture Association of America (MPAA) rating aims to limit underage children to watching films that are not suitable for their age. In recent years, there has been graduation degradation" with more adult languages, material inducements and increased frequency of sexual content. Policy changes and psychological processes that affect MPAA evaluators and the rating process are seen as credible reasons for the spread of ratings, as well as the impact of these rating changes on media consumers and society as a whole. ${ }^{11}$ In the eyes of Zhong Dafeng (2015), the film grading system essentially establishes a set of social value standards for film content. A film that is rated as suitable for everyone to watch means that the content contained in it is basically in line with the positive values of society. The part that will be allowed to be watched with age increasing is because those who have certain experience and resolution can view it, and naturally it has a certain negative or controversial value. The higher the level of a film is, the more complex it is to discern. In fact, it has established a standard system for the - rainstream" and positive" content and value standards of society. ${ }^{12}$

Russian scholar Maxim Duula (Максим Туула), in " System of Age Ratings (Restrictions) in Russia: Revolution or Profanation?" made discussions on the Russian film grading system, and induced and summarized the film grading experience in Germany, France, the United States, Estonia and other countries. Film grading is based on different film themes: for example, sex, nudity, violence and slang, drugs, ethnic, racial and religious discrimination, antisocial behavior, etc. (suicide crime, corruption, marriage and marital problems, divorce and other emotional trauma, alcohol dependence, death and serious illness). The scholar believes that the existing subject classification can be carried out: such as child sexual abuse, unreasonable sadism, excessive violence and cruelty, the use of weapons and torture, chauvinism and ethnic exclusion, racism, propaganda wars, incitement to overthrow the political system .

Due to the complex influence of movies on ideology, some scholars believe that the film grading system is weakly binding, so, legal review should be strengthened. Regis Dubois (2014) believed that most films are based on a moral, aesthetic, and political consensus and converge with the country's mainstream thinking, but the film is quite complex in terms of ideology. He put that in the 1980s and 1990s, the power of large-scale film studios was strengthened, and the demands of money and business made the content of the film high-file more than ever. On the one hand, the film grading system has been relaxed, and ethical standards have changed; on the other hand, film censorship has become more rigorous and binding. For the film grading system, the film rating criteria were subject to external pressure from the film company. ${ }^{13}$ Lawrence M. Friedman (2014) argued that ethics is an important theme of filmmaking. The film has brought

11 Richard Potts, Angela Belden. Parental Guidance: A Content Analysis of MPAA Motion Picture Rating Justifications 1993-2005, Current Psychology, 2009, 28 (4):266-283.

12 Zhong Dafeng: American Film Grading System and Social Value Construction, the first issue of Journal of Beijing Film Academy in 2015.

13 Same with note 6 many negative effects to the society. Many "criminals" have learned "criminal means" from the film, so the film listing requires legal review. On the issue of freedom of speech, he pointed out that the position of the US Supreme Court is clear: the law does not have the right to offend speech freedom. But because the film may be "used for evil purposes," the state has the right to manage it. Movies do sometimes express opinions and serve as "media of thought." But at the same time, movies may corrupt morality. Film companies are profitable groups, and they are not sheltered by liberty of expression. Legal review is an acceptable form of control. ${ }^{14}$

However, in public's eyes, too strict film censorship and grading system may limit the development of the film industry. Joshi Hemant (2017) presented the dilemma facing the Indian film review. The Centre Board of Film Certification (CBFC) will review films before the public screening in accordance with the Indian Film Act. It is up to CBFC to decide whether it should be publicly screened in an open manner or to make certain cuts and changes. However, due to the time of review and the risk of content deletion, film censorship has gradually become an obstacle to the development of Indian films. Recently, the CBFC filed 89 amendments to a drug-related film, so that the film company resorted to a lawsuit against the CBFC in the Mumbai High Court. The court finally supported the film company's claim. Yet, the development of Iranian films clearly contradicts the idea of restricting development." Ziba Mir-Hosseini (2016) pointed out that after the introduction of the Iranian film censorship system, many people predicted that the new review restrictions were too strict to kill Iran movie industry. ${ }^{15}$ However, Iranian films have undergone significant changes at the same time as the extensive changes in Iranian culture and society. Iranian film is recognized as one of the most innovative and exciting films in the world. The key to resolving this contradiction is to understand the relationship between art, society and the state. ${ }^{16}$

Jonathan Todres (2015) argued that scholars should pay more attention that the film descriptions were out of realworld issues as to how to balance the relationship between the development needs of the film industry and the review rating. Researchers and advocates can use the film to provide an opportunity to educate the public about the realities of the problem. Movies and television can be powerful tools for education, but what important is that they shall be used effectively. By means of the films, the researchers and advocates are allowed to engage in more inclusive discussions on real-world issues and respond to them in a comprehensive manner. It's wise for scholars and advocates to work together to ensure that decision makers rely on evidence-based research and other important information to develop legal and policy responses, which means that laws and programs should be assessed to ensure evidence-based research can be carried out to better understand problems, assessing the effectiveness of responses. Meanwhile, it's necessary to work with

\footnotetext{
14 Same with note 7.

15 Joshi Hemant. Indywood. The Indian Film Industry. Deloitte. Retrieved 2 June 2017.

16 Ziba Mir-Hosseini. Iranian Cinema Art, Society and the State. Middle East Report , 2001
} 
survivors and risk communities to ensure that their expertise passes legal and policy initiatives. ${ }^{17}$ Feng Liming (2013) believed that there was a tension between film censorship and freedom of expression, which was determined by that film censorship meant a limitation on the characteristics of film expression in nature. It's more the conflicts between state power and citizens' individual rights than between film censorship and freedom of expression. Therefore, viewing from the angle of constitutional law, the key to balancing the relationship between film censorship and expression freedom means balance the relationship between state power and individual citizenship. ${ }^{18}$

\section{CONCLUSION}

Whether in the birthplace of the film or in the flourishing place of film development, film censorship and grading as an institutional tool can not only protect the legitimate rights and interests of minors, but also play an important and irreplaceable role in social norms and even ideology. The censorship and grading system of the film does vary according to the degree of development of spiritual civilization and material civilization in different countries. More and more developed countries in the film industry have begun to think about how to further rationalize the system, thereby achieving its proper protection and regulation, and promoting the rapid development of the national film industry. For China, there is no separate film grading and censorship system at present. The grading and review work is basically carried out by the department of the State Administration of Radio and Television. On the one hand, the emergence of this situation is related that the development of China's film industry is still in the "industrial naive period", and on the other hand, it is also because of China's political system. Based on this reality, it is necessary to establish a film grading and censorship system in China as soon as possible.

\section{REFERENCES}

[1] Remi Fournier Lanzoni: "French Film - from Birth to the Present", The Commercial Press, 2009.

[2] Christian Mets. Essais sur la signification au cinema, Paris: Klincksieck, 1968

[3] Zhu Hong: History of Contemporary French Film (19591980)",Beijing: Communication University of China Press, 2011

[4] Burch, Noel (textes choisis, traduits et présentés par), Revoir Hollywood: la nouvelle critique anglo-américaine, Nathan, Paris, 1993.

[5] R. La Guerre froide dans le cinema d'espionnage, Paris: Henri Veyrier. Lacourbe, R. (1985)

[6] Regis Dubois: Hollywood - Film and Ideology. The Commercial Press, 2014 (7).

[7] Lawrence M. Friedman. Human rights, freedom of expression, and the rise of the silver screen, Hofstra Law censorship, 2014.

[8] Battles Ben. Terror, Tort, and the First Amendment, Brooklyn Law censorship, 2006. In this article, Battles Benzai critically accepted the view of Nicholas D. Kristof

17 Same with note 8 .

18 Feng Liming: Chinese Film Censorship in the Perspective of

Expression Freedom, the fifth issue of "Exploration and Contention" in 2013
[9] Jonathan Todres. Human trafficking and film: How popular portrayals influence law and public perception, Cornell Law censorship Online, 2015.

[10] Richard Potts, Angela Belden. Parental Guidance: A Content Analysis of MPAA Motion Picture Rating Justifications 1993-2005, Current Psychology, 2009, 28 (4):266-283.

[11] Zhong Dafeng: American film classification System and Social Value Construction, the first issue of Journal of Beijing Film Academy in 2015.

[12] Lucille M. Ponte .Coming Attractions: Opportunities and Challenges in Thwarting Global Movie Piracy, American Business Law Journal, 2008

[13] Joshi Hemant. Indywood. The Indian Film Industry. Deloitte. Retrieved 2 June 2017.

[14] Ziba Mir-Hosseini. Iranian Cinema Art, Society and the State. Middle East Report , 2001

[15] Feng Liming: Chinese Film Censorship in the Perspective of Expression Freedom, the fifth issue of "Exploration and Contention" in 2013. 